\title{
NOVEL MAGNETIC MICRO- AND NANOPARTICLES FOR BIOMEDICAL SEPARATION AND AS MEANS FOR A NEW APPROACH TO AIDS THERAPY
}

\author{
DETLEF MÜLLER-SCHULTE \\ Institut für Anorganische Chemie, RWTH Aachen, \\ Professor-Pirlet-Str. 1, D-52074 Aachen, Germany
}

(Received 26 January 2000; In final form 2 February 2000)

\begin{abstract}
The separation principle and the advantage of using magnetic polymer particles in bioseparation is elucidated. After a short review of the presently used diverse magnetic microparticles as well as the basic differences of micro- and nanosized magnetic particles with regards to their physical properties in bio-separation, preparation and application of novel magnetic microparticles prepared from polyvinylalcohol are described. The performance of the novel product and their superior properties over established products in diverse bioseparation tests are shown. Furthermore, nanoparticles used for a new AIDS therapy approach are described. The basic principle is explained by which the AIDS virus (HIV) is destroyed through heat generated by inductively heated magnetic nanoparticles, which are specifically attached to the virus. Inductive heating tests with model magnetic colloids show that the required temperatures of $>50^{\circ} \mathrm{C}$ can easily be achieved.
\end{abstract}

Keywords: Magnetic polymers; Nanoparticles; Bioseparation; Magnetic fluids; AIDS; Hypothermia

\section{INTRODUCTION}

Magnetic polymer particles are being increasingly used in the field of biosciences to separate, analyse and diagnose cells or bio-molecules such as antibodies, DNA-molecules, proteins, hormones or antigens.

These magnetic polymer particles are referred to as magnetic beads. They are preferably spherically shaped and consist of a polymer 
matrix in which a magnetic colloid, e.g., magnetite, is encapsulated. This gives the polymer particle its magnetic properties. The magnetic beads used for the tasks mentioned above generally have a particle size of between 1 and $20 \mu \mathrm{m}$. Specific ligands are chemically coupled to the polymer matrix to separate bio-molecules or cells. These ligands can selectively bind to the bio-molecules or cells, respectively. These target substances can then be separated from the substance mixture for subsequent analysis simply by holding a hand magnet to the reaction vessel. The basic principle of magnetic separation is shown schematically in Figure 1.

The use of magnetic polymer particles has two decisive advantages over classic chromatographic separating methods:

(i) one works in a suspension so that the reaction kinetics corresponds to that of a quasi homogeneous solution,

(ii) due to the exceptional fineness of the magnetic particles to conventional separation media (particle sizes in general: 10$150 \mu \mathrm{m})$ resulting in much larger surface areas, the separating processes can be shortened by factors of between 10 and 100 .

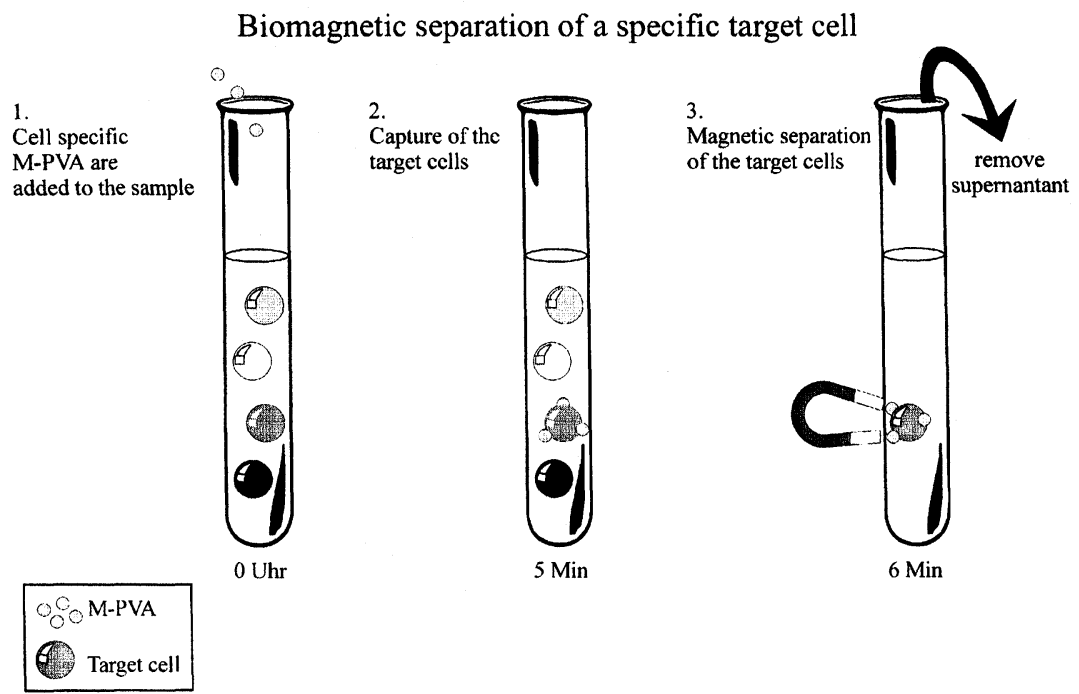

FIGURE 1 Separation principle using magnetic polymer beads. 


\section{PRESENT STATUS OF THE MAGNETIC PARTICLE TECHNOLOGY}

Starting from magnetic particles on the basis of agarose-polyacrylamide, polyacrylates, agarose-polyaldehydes, polyglutaraldehydes, polyacrolein, agarose and starch [1-7], magnetic beads of polystyrene and polyderivatives have become the most commonly used media over the past ten years. Special mention should be made here of the pioneering work carried out by Ugelstad et al. $[8,9]$, who were able to produce monodisperse magnetic particles using emulsion polymerisation. The method requires a number of post-swelling and - derivatisation steps to finally obtain the desired magnetic particles. This type of bead production is also basically used by other bead manufacturers to produce magnetic particles on the basis of polystyrene.

Despite the widespread use of such beads, there are still some drawbacks in connection with their usage. These relate especially to the laborious synthesis of such beads and to the predominantly used polymer, polystyrene, which exhibits distinct hydrophobic properties resulting in pronounced and hence residual unspecific protein adsorption, producing an undesirable background signalling in immunodiagnostics (immunoassay). Thus, there is in general still scope and need for the development of magnetic beads which exhibit low unspecific bio-molecule adsorption combined with a high ligand binding capacity and pronounced dispersion properties.

Apart from magnetic particles in the micrometer range, magnetic nanoparticles have also been described over the past twenty years [1012]. Two basic methods have become predominant from amongst the multitude of various methods to produce magnetic nanoparticles. The first method consists of producing iron oxide powder of the required fineness by means of a very time-consuming ball-milling process. In order to disperse the magnetic nanoparticles in an aqueous medium, dispersion stabilisers in the form of charged surfactants (e.g., oleic acid, petroleum sulphonate, sodium alkylnaphtalene sulphonate, alkylaryl sodium sulphonate) [13] are added during milling. These magnetic colloids also known as ferrofluids, display a permanent magnetisation, which is randomly distributed due to the thermal movements in the fluid and is thus compensated, i.e., the fluid displays no permanent magnetism. These types of ferrofluids are used 
technically wherever controllable forces are required. In view of the number of potential applications, documented by over 1500 patents alone [14], we will only mention by way of magnetic particles their use in sliding bearings, shaft seals, as attenuation media in loudspeakers and as sealing media in mechanically moved parts.

Since the aforementioned method is very time consuming and to enable the simple use of magnetic nanoparticles in biotechnology, magnetic nanoparticles are today primarily produced through the precipitation of iron (II)/iron (III) solutions of defined concentrations and compositions by means of a base. The particles obtained can then be dispersed in an aqueous medium by adding a stabiliser. Stabilisers such as proteins (e.g., serum albumin, antibodies) as well as polysaccharides (e.g., dextran, starch) have proven to be suitable for this purpose $[15,16]$.

Ferrofluids obtained in this manner could thus be used in the very promising field of medical diagnostics and therapy. Examples include immunoassays [15], drug targeting within cancer therapy [17], as contrast agent in magnetic resonance imaging $[16,18]$ as well as for the separation and characterisation of cells and biomolecules [19].

The main difference when handling micro and nanoparticles is that magnetic forces are proportional to the volume of the particles. Hence, in order to make this force among nanoparticles comparable to the thermal force of the Brownian motion and to achieve an appropriate quantitative separation, very high magnetic fields and field gradients have to be generated. This is achieved in practice by passing the fluid suspension through a test tube or column densely packed with stainless steel wool which is being magnetised by an externally applied magnetic field (either permanent magnet, e.g., Neodymium-Iron-Boron magnet, or electromagnet).

In the following, novel magnetic polyvinylalcohol microbeads for bio-separations are reviewed which are synthesised using a suspensioncrosslinking technique. Furthermore, magnetic nanoparticles are described which are designed for a new AIDS therapy approach.

\section{MAGNETIC POLYVINYLALCOHOL BEADS}

Polyvinylalcohol (PVA) was used for the synthesis of the new magnetic particles since compared to other polymer matrices such as 
polystyrene, polyacrylates, polyaldehydes and serum albumin $[4,5,8,20]$ this polymer offers a number of advantages such as chemical functionality, hydrophilicity, availability and cost efficiency, aspects of which are discussed in detail elsewhere [21]. The beneficial properties of the hydrogel-like PVA are substantiated by a number of successful bio-applications such as controlled drug delivery [22-24], contact lens manufacturing [25], immobilisation of enzymes [26], magnetic adsorbent in the pharmaceutical industry [27], separation membrane in reverse osmosis, dialysis and pervaporation [28-30], bioartificial materials [31], optic sensor development [32]. Hence, it is the polymer of choice also to fulfil the basic prerequisites for bioseparation purposes.

The magnetic beads are produced by means of a newly developed water-in-oil suspension cross-linking method using the mechanical dispersion of an aqueous polyvinylalcohol solution in common vegetable oil. A magnetite colloid is finely dispersed in the solution. Drop-shaped polymer particles are formed during the suspension process and are subsequently fixed by adding a cross-linking agent $[21,33]$. Figure 2 shows a typical SEM microphotograph of the produced PVA beads. The overall process is completed within 10 to 15 minutes. Conventional magnetic bead manufacturing methods normally require between 20 and 40 hours in comparison [9].

The suspension method to produce magnetic particles is a new development characterised by a number of adaptable process technology parameters such as:

- viscosity of the oil and polymer phase

- stirring speed

- stirrer and stirring vessel geometry

- molar mass and concentration of the polymers

- concentration and type of emulsifiers in the oil and polymer phase.

These process parameters enable the production of various magnetic particles which can be ideally adapted to the respective analysis and separation task with respect to their size, surface morphology, porosity, mechanical properties $[34,35]$. The following Table I reviews some process and product technology relationships for PVA bead production.

As the aforementioned magnetic nanoparticles or ferrofluids, respectively, can be used as magnetic colloids for the PVA bead 
홍

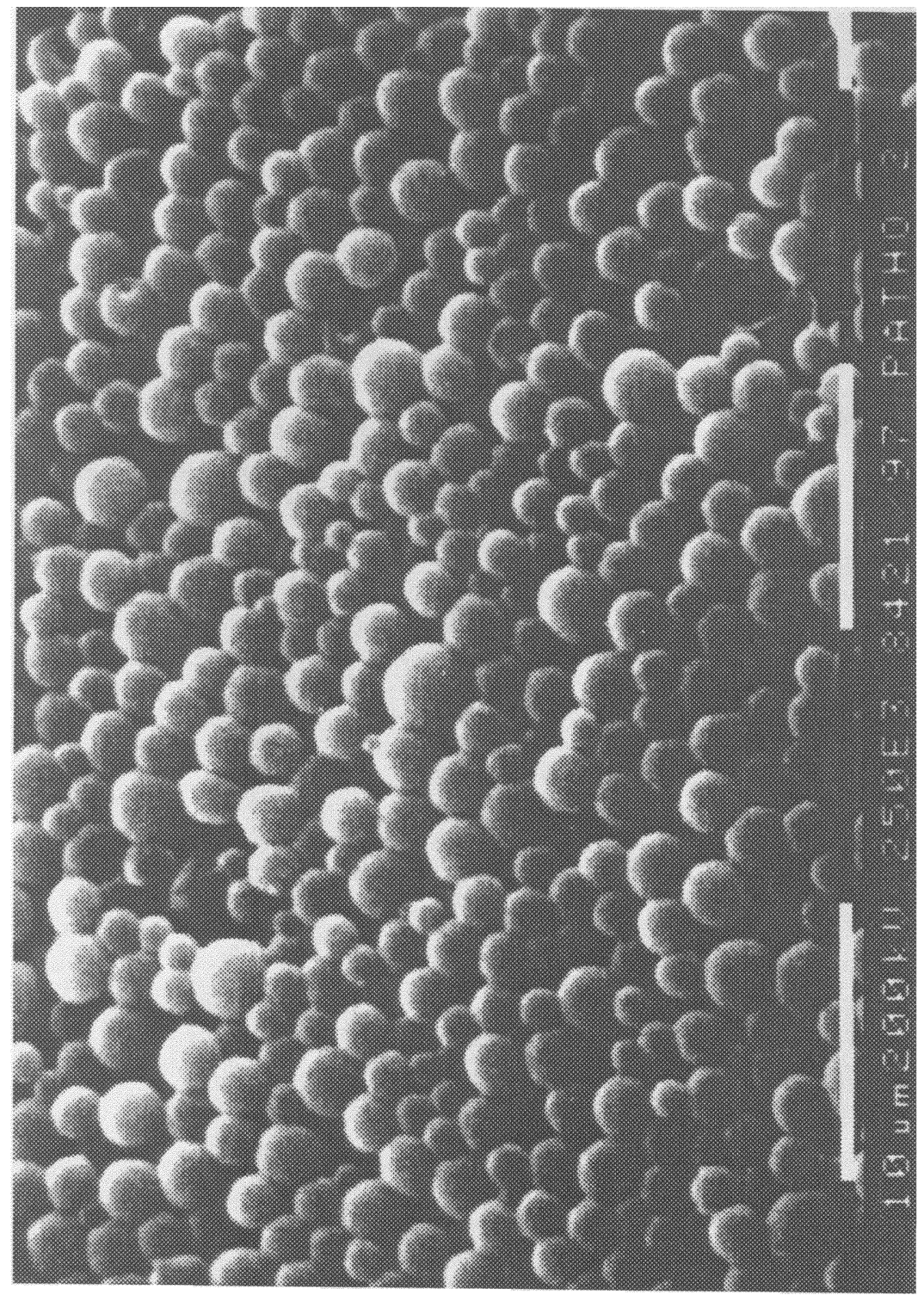

氠

อี

휼

ํ.

.

紊

.

0
5
0
0
0
0
0
0
0

츠

ठั.

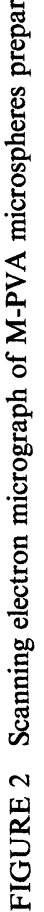


TABLE I Effect of process parameters in the water-in-oil suspension-cross-linking technique on the size of the M-PVA beads

\begin{tabular}{lcl}
\hline Parameter & Parameter change & Bead size \\
\hline Oil viscosity & decrease & increase \\
PVA phase viscosity & decrease & decrease \\
Polymer concentration & increase & increase \\
Molar mass of PVA & increase & increase \\
Volume aqueous phase & increase & increase \\
Oil amount & increase & increase \\
Emulsifier concentration & increase & decrease \\
Stirring speed & increase & decrease \\
\hline
\end{tabular}

synthesis, magnetic particles can be produced with a high iron content $(20$ to $60 \% \mathrm{w} / \mathrm{w})$. This enables a very rapid and efficient magnetic separation, one prerequisite for the automation of magnetic bead separation. Comparable magnetic particles on a polystyrene basis all have a magnetite content of 5 to $20 \%$ [9].

\section{GENERAL PROPERTIES AND FEATURES OF PVA MAGNETIC BEADS}

The special features of the new beads result from the chemical structure of the hydroxyl groups containing PVA. They fulfil two main prerequisites for applications in bioseparation: (i) hydrophilicity and (ii) high functionality.

As a result of its chemical structure, PVA represents a hydrogel that shows minimal unspecific protein adsorption compared to other carrier media $[35,36]$. This feature makes the matrix particularly suitable for protein affinity separations. On the other hand, the presence of $\mathrm{HO}$-groups provides a broad chemical functionality which comprises anionic $\left(-\mathrm{COO}^{-},-\mathrm{SO}_{3}^{-}, \mathrm{SO}_{4}^{-}\right)$, cationic groups $\left(-\mathrm{NHR}_{2}^{+},-\mathrm{NR}_{3}^{+}\right)$, hydrophobic $\left(-\mathrm{C}_{18}\right)$ as well as activated groups for direct bio-molecule coupling such as: epoxy, isocyanate, aldehyde, tresyl/tosyl groups [21].

A further essential aspect in the use of magnetic beads is their dispersibility in aqueous media, which is determined by their density and fineness. On the basis of the diverse adaptable process parameters, PVA beads with various specific densities $\left(e . g .,<1.2 \mathrm{~g} / \mathrm{cm}^{3}\right)$ can be obtained which promote the overall dispersibility. Comparative 
sedimentation experiments with commercial magnetic particles (Dynabeads M-280; Dynal, Norway) led to a 12-hour settling half-life for PVA beads compared to about 1.5 hours for Dynabeads ${ }^{21)}$. Since optimally dispersed particles enable a kinetic reaction similar to that in a homogenous solution, PVA beads open up new perspectives, especially for immunoassays where submicron particles were previously in common use due to their dispersion properties. The disadvantage of such particles is that an additional high-gradient magnetic field is necessary ( $c f$. above), whereas the microsized beads can be separated by means of a simple hand magnet.

The last two decades have witnessed an increasing trend in the use of polymer microcarriers as targetable drug carriers and also as extracorporeal adsorbents to remove specific toxins from blood, plasma or serum. Prominent examples are the removal of immunoglobulins in the treatment of hemophilia [37], the reduction of low density lipoprotein for the treatment of hypercholesterolemia $[38,39]$ or the clearance of toxic metabolites to assist hemodialysis [40, 41]. For further details of the therapeutic applications, we refer to a number of excellent papers and reviews $[40,42]$.

It can be seen that the aspect of biocompatibility plays a crucial role for the biomedical application of magnetic particles. As mentioned above, PVA, a hydrogel, is biologically inert [43], adsorbs distinctly less protein than other polymer materials and should therefore exhibit excellent biocompatibilities. This has been corroborated in recent platelet tests revealing an about 8 to $12 \%$ platelet depletion caused by the PVA media in comparison with other commercial media showing a depletion between 32 and 44\%. Likewise, PVA beads incubated with HeLa- (a commonly used tumour cell line) and human endothelial cells revealed a virtually unimpaired DNA synthesis rate and protein metabolism compared to control cells [21].

\section{APPLICATIONS OF MAGNETIC PARTICLES}

Separations using magnetic particles exploit the affinity principle. Specific ligands are hereby coupled to the surface of magnetic beads. These ligands display complementary structures to specific sites of biomolecules or cell receptors so that these target substances 
specifically bind to the magnetic particles. Examples of such types of ligands include proteins, antibodies, oligosaccharides or nucleic acids.

\subsection{Blood Group Antibody Separation}

Due to the favourable physiological properties of PVA carriers and the successful use of non-magnetic PVA beads as adsorbents for low density lipoprotein and blood group antibodies [34,39], magnetic PVA beads were developed as an adsorbent to eliminate blood group antibodies. This plays a crucial role in bone marrow transplants, where 10 to $15 \%$ of the patients suffer from an $\mathrm{ABO}$ incompatibility and the bone marrow donor experiences acute haemolytic reactions [44].

Antibody adsorption tests were conducted on human plasma group 0 using 80 to $120 \mu \mathrm{m}$ sized PVA beads to which a blood group A ligand was attached. The adsorption capacities achieved with the PVA adsorbent were 30 to $50 \%$ higher in comparison to a commercial silica gel adsorbent $[21,34]$.

\subsection{Cell Separation}

Another application of magnetic particles in medicine arises from the possibility of separating and isolating cells. This can be achieved using magnetic bead separation because the availability of pure cell populations has become an essential part of laboratory testing as well as clinical research $[4,5,8]$.

The principle of separation is based on the fact that practically all body cells bear specific $\mathrm{CD}$ receptors $(\mathrm{CD}=$ cluster of differentiation) on their surface which determine the specific functions (e.g., maturation, proliferation, immune response etc.) of the cells in the body. These CD receptors are the cells' "password" in a manner of speaking. By coating the magnetic particles with antibodies against the respective $C D$ receptors, all types of cells such as T-lymphocytes, Blymphocytes, granulocytes, leucocytes, monocytes, denditric cells, natural killer cells can in principle be isolated from the corresponding body fluids (e.g., blood, bone marrow, spleen, urine) or corresponding cell cultures. 
The magnetic bead technology opens up particularly interesting perspectives for the therapy and diagnosis of tumours. The quantitative isolation and determination of tumour cells from tissue samples can on the one hand provide information on the progress of a therapy and on the other, the magnetic bead technique has proven itself to be very promising for the separation of tumour cells during bone marrow transplants [8].

The binding of CD4-positive T-lymphocytes to PVA magnetic particles coated with antibodies against the CD4 receptors is shown in Figure 3 as an example of cell separation.

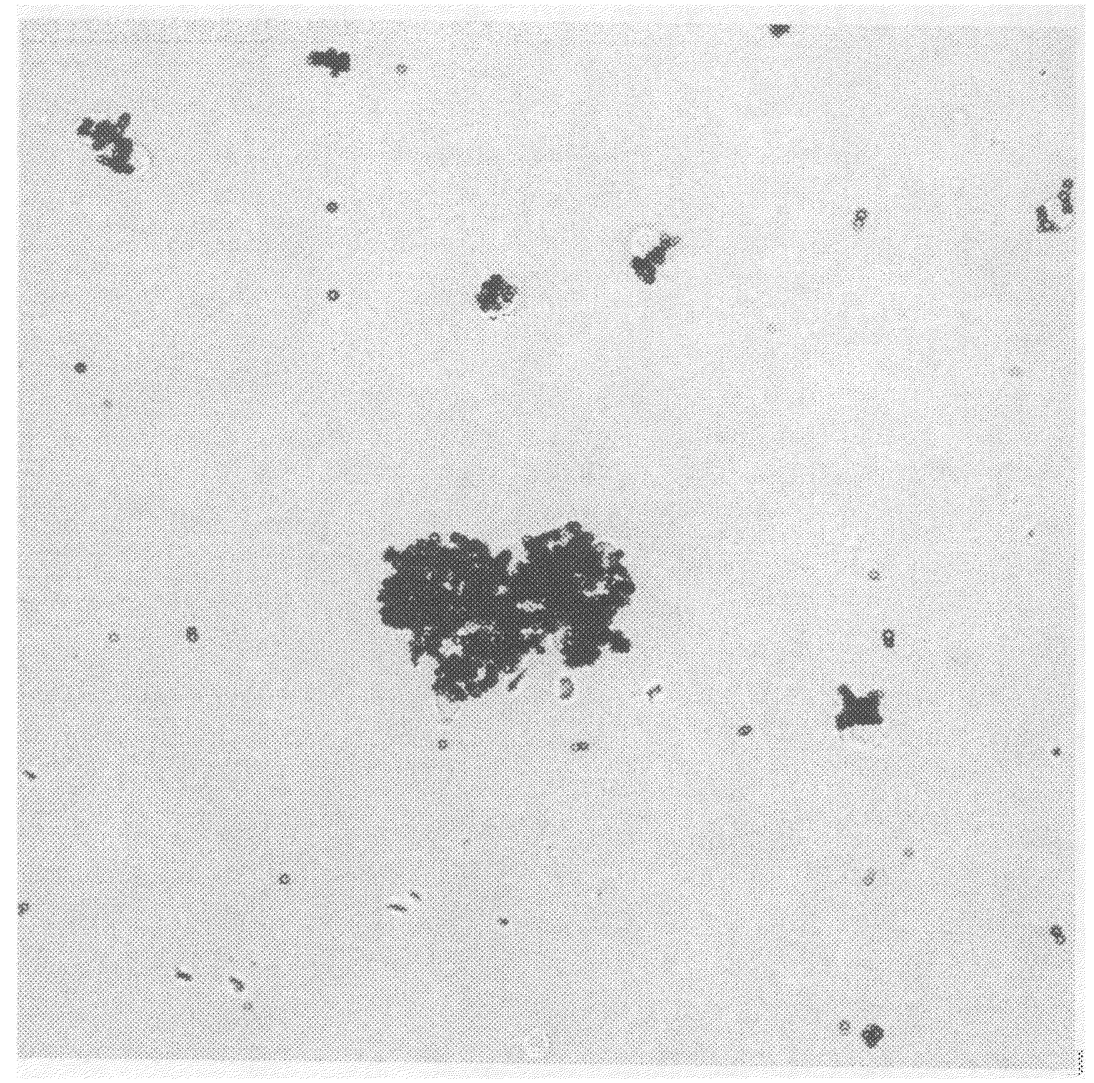

FIGURE 3 In vitro test demonstrating the binding of CD4 positive T-lymphocytes to anti-CD4 antibody coated magnetic PVA beads. 


\subsection{Immunoassay}

The antibody-antigen interaction to determine the concentration of certain toxic or pathogenic substances (antigens) in diagnostics has been in use for many years. The separation principle and procedure are explained in Figure 4 taking the immunoassay - also called competitive immunoassay - using magnetic beads as an example.

In the first step, a certain amount of the substance containing the antigen, which is being analysed, is added to a defined amount of the

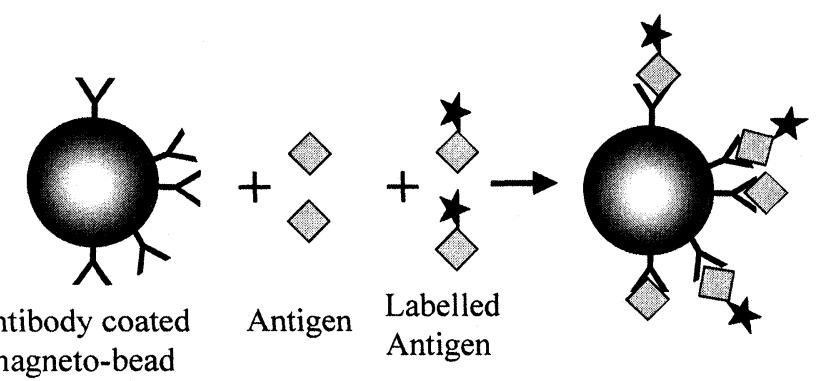

magneto-bead

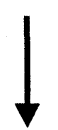

Y Antibody

$\diamond$ Antigen

Magnetic

* Label

separation

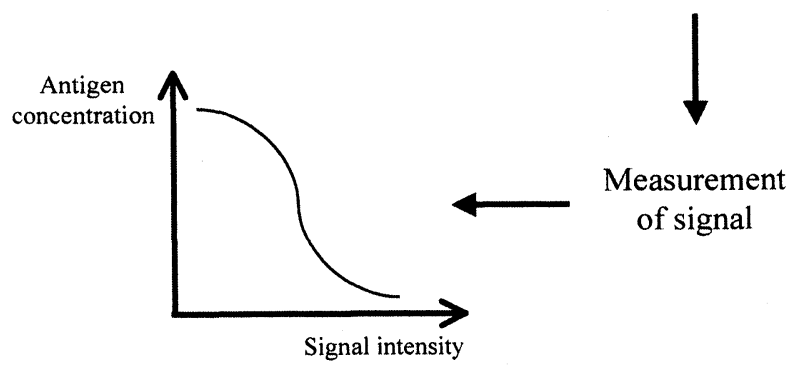

Evaluation of data by comparison with calibration curves

FIGURE 4 Diagrammatic representation of a competitive immunoassay using labelled antigens. 
same, but labelled antigen. This label can, for example, be a radionucleid, a fluorescent dye or an enzyme (e.g., peroxidase) which produces a colour reaction.

The second step comprises incubation with the magnetic particles coated with the antibodies. The antibodies are specific to the respective antigen. After binding of the antigen to the antibody, the magnetic beads are separated from the supernatant by applying a magnet. The resulting signal (radioactivity, fluorescence e.g.), which is evaluated on the basis of a calibration curve, is inversely proportionate to the antigen concentration being investigated. The detection limit for this method is $10^{-14} \mathrm{~mol}$ per litre.

Since the antigen - antibody reaction occurs in a quasi homogeneous phase and the magnetic particles can display an enormously large surface on account of their fineness, the analysis times can be reduced between 10 and 20 -fold compared to the classic microtiter plate method. This method is thus suitable above all for quick tests and also offers the possibility of automating routine tests [45].

\subsection{Nucleic Acid Analysis}

Apart from the classic diagnosis method by means of the antibody antigen detection, molecular biology analysis in the form of the genetic analysis of pathogens such as viruses, bacteria and fungi has become very important in medical diagnostics over the past few years. The importance of the method becomes clear if one considers the example of an AIDS infection. Whereas conventional antibody detection methods only allow clear statements of a primary infection after five weeks at the earliest, the virus can be proven after only one day using gene diagnostics, a factor which is of paramount importance in everyday medical practice.

In view of the variety of different methods, we will only discuss the hybridisation by means of immobilised DNA/RNA probes in more detail at this point. For this purpose, as shown schematically in Figure 5, the DNA target sequence in question - i.e., the DNA sequence specific for the respective pathogen - is coupled to the magnetic particle as a single strand. The target sequence is then captured by incubating the magnetic DNA probe with the substance (e.g., blood, serum, plasma, urine) which contains the pathogenic DNA to be detected. This can then be separated from the 
Bead bound target-DNA

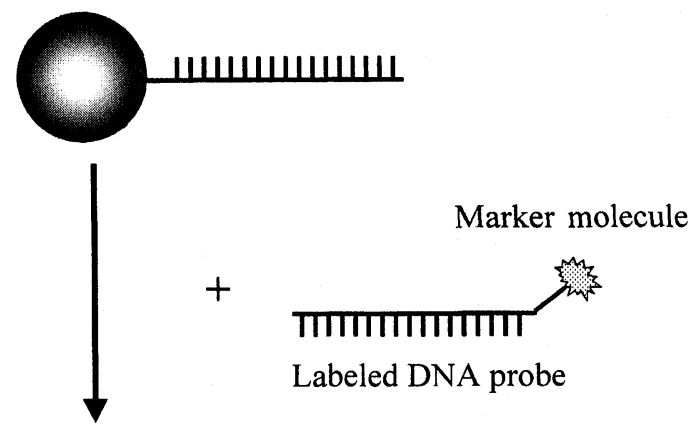

Hybridisation
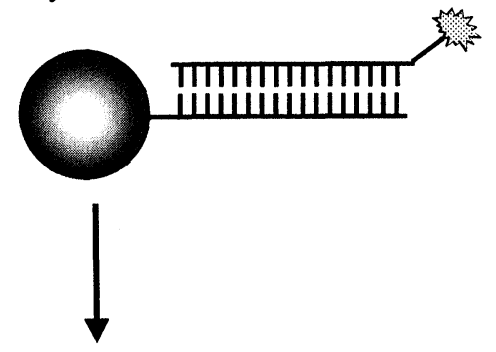

Magnetic separation

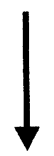

Detection of marker signal

FIGURE 5 Diagrammatic representation of a DNA detection using labelled DNA probes.

heterogeneous substance mixture using a common hand magnet and detected by means of conventional DNA analytical means (e.g., fluorescence, radioactivity, luminescence). This method of magnetic bead hybridisation is also ideal for the separation and analysis of gene libraries in an analogous manner [46, 47].

\subsection{Nucleic Acid Extraction}

DNA/RNA extraction from crude sources is becoming increasingly important in the course of molecular biology analysis. Cationic and 
non-charged chromatography columns based on silica gel are nowadays used in everyday practice to separate the nucleic acids. This completely circumvents an extraction method using the toxic phenol. Since the PVA beads, as explained above, also permit the introduction of ionic groups into the matrix, interesting possibilities are opened up whereby magnetic particles can be used for DNA extraction. This can be, for example, via cationic groups in the form of tertiary or quaternary ammonium groups (e.g., diethylaminoethyl-) to which the negatively charged DNA can bind.

A further possibility that has recently been described consists of binding the DNA to be isolated to beads containing carboxyl groups. This surprising binding behaviour of the DNA to an anionic carrier is made possible by adding high polyethylene glycol and $\mathrm{NaCl}$ concentration [48]. Thus, DNA plasmids could be isolated from E.coli strains within 5 minutes using carboxylated PVA beads [49]. The particularly aspect of this separation method undoubtedly lies in the interesting perspective of automating this technology through the use of magnetic particles.

\subsection{Streptavidin Magnetic Beads}

Among the diverse carrier media for separation, streptavidin and avidin-coated media have certainly become one of the most widely used matrices in current separation technology [50]. The background of the streptavidin/avidin method, based on the extremely high affinity between streptavidin/avidin and biotin $\left(K_{d}<10^{-15} \mathrm{M}\right)$ which surpasses even that of the antibody-antigen bond, has been reviewed extensively elsewhere $[50,51]$. Thus, a mention of the most important applications of this carrier type will suffice here. These are DNA sequencing, PCR technology, purification of DNA proteins, gene assembly, hybridisation capture of specific target RNA/DNA and cell bacteria isolation $[50,51]$.

The widespread application of the strepavidin carrier has been primarily enabled through the constant improvements in controlling the biotinylation methods for a variety of target substances - above all single stranded oligonucleotides. A further precondition for the optimum use of this carrier type is an optimal coupling of the streptavidin to the respective matrix. Recent avidin and streptavidin 
immobilisation tests with PVA beads using various coupling methods have shown that this carrier provides excellent conditions for high streptavidin/avidin immobilisation with a simultaneous high biotin binding $[21,52]$.

\subsection{New Aids Therapy Approach Using Magnetic Nanoparticles}

Apart from using magnetic forces for purely separation purposes, a further effect can be used which is a direct result of the magnetic colloid: ferri- and ferromagnetic substances can be inductively heated in a magnetic alternating field-generated by a magnetic coil analogous to a microwave. This effect can be used for a completely new approach in the AIDS therapy. Almost all therapeutic measures employed today against the AIDS virus HIV (Human Immunodeficiency Virus) use specific inhibitors of viral enzymes, which regulate the viral infection mechanism. Although some of these compounds can significantly reduce the virus load, there is still some scepticism about the long-term perspectives of this therapy since the severe side effects of the drugs are still almost uncontrollable. Neither has the development of a prophylactic inoculation as yet led to any tangible result.

Our approach is not based on new drugs. Rather, we attempt to bind the HIV to specially developed magnetic nanoparticles, which can then be inductively heated to irreversibly inhibit the virus. Either starch stabilised magnetic nanoparticles or magnetoliposomes are used as magnetic nanoparticles for the new therapy approach. The synthesis of these magnetic nanoparticles is described in detail elsewhere [52, 53].

It is known that the HI-virus can be irreversibly deactivated at temperatures between 50 and $60^{\circ} \mathrm{C}$ [52]. Extremely fine magnetic particles with a size of 30 to $50 \mathrm{~nm}$ which have been brought up to the necessary temperatures through external inductive heating are, according to the new approach, injected into the body. Setting the frequency to between 0.8 and $5 \mathrm{MHz}$ ensures that only the magnetic particles are heated up; the remaining body tissue is not affected by this treatment.

In order to target the particles to the viruses, we exploit the same biochemical mechanism that leads to the primary infection with HIV in the human body. CD4 receptors are hereby chemically coupled to 
magnetic nanoparticles. These are the receptors, which the HI-virus uses to enter and infect the T4-helper cells, the main targets of the HIV. As soon as the magnetic particles have bound to the viruses they can then be inductively heated to the necessary temperature of over

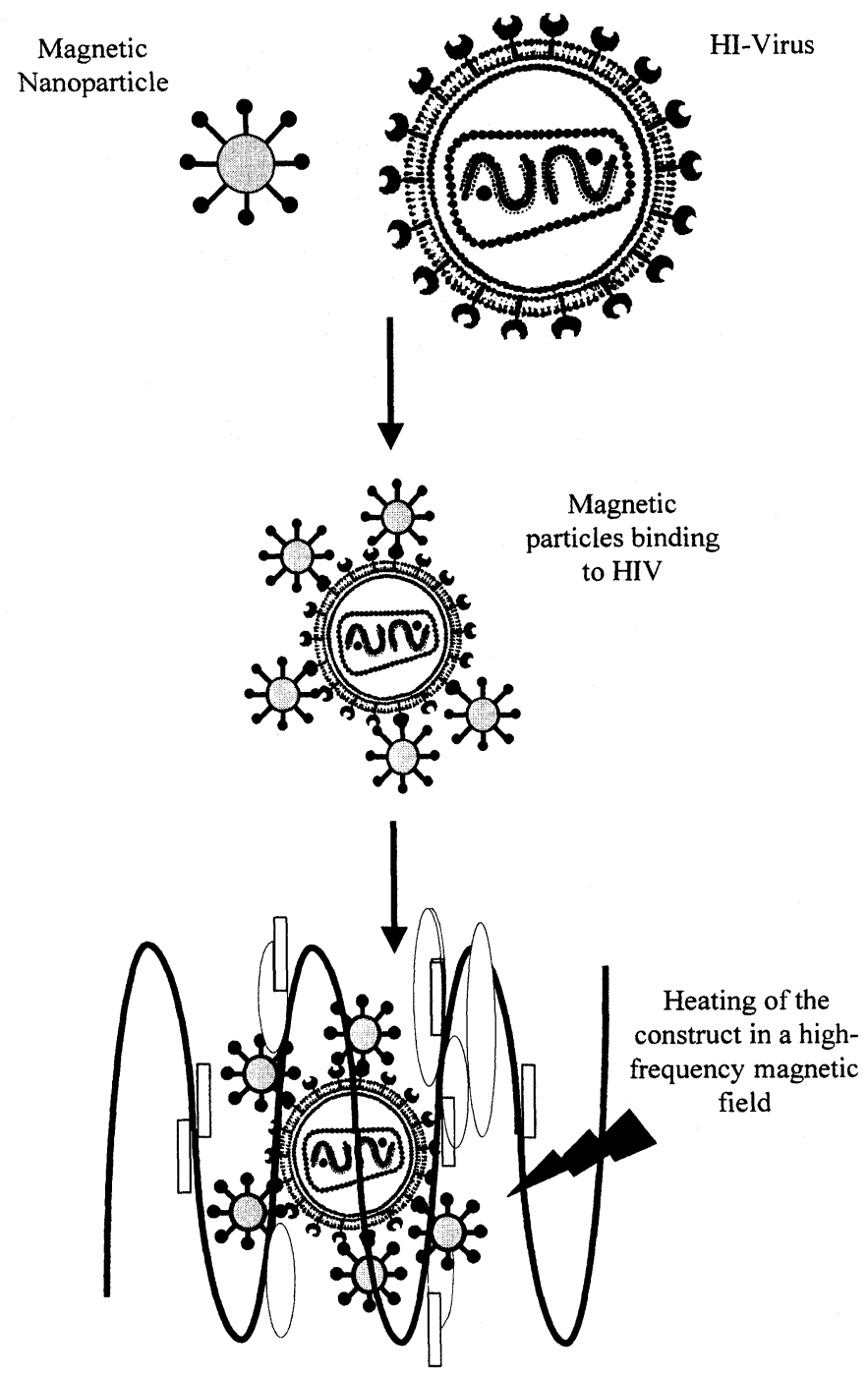

FIGURE 6 Schematic representation of the AIDS therapy approach using CD4 coated magnetic nanoparticles. 


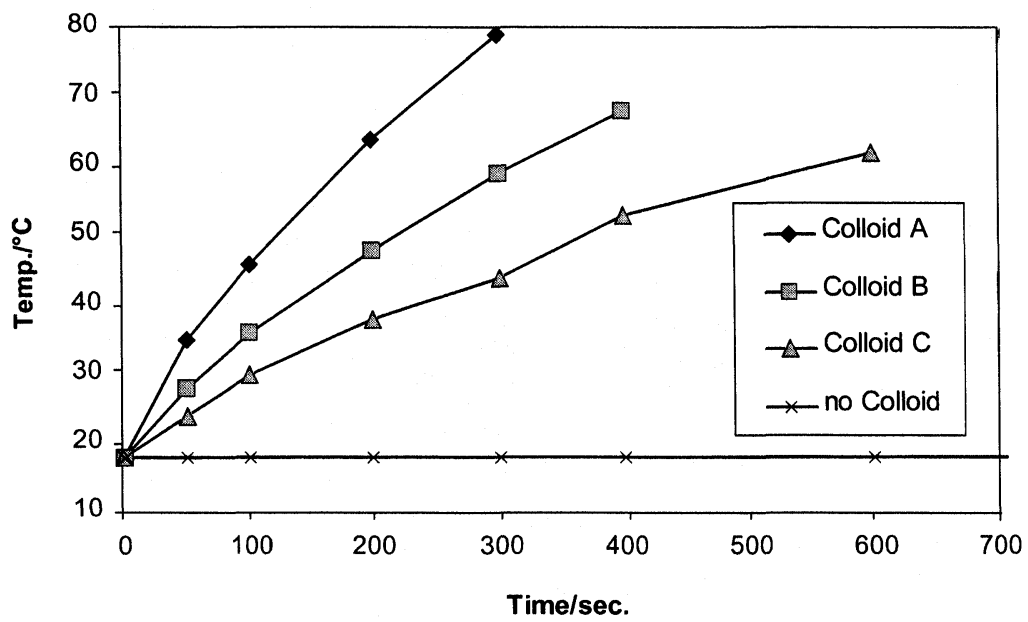

FIGURE 7 The temperature-time profiles obtained by induction heating for various magnetic colloids. A: starch stabilised (3.5\% iron), B: starch stabilised (2.8\% iron), C: PVA stabilised (2.5\% iron), D: distilled water with no colloid.

$50^{\circ} \mathrm{C}$ by the aforementioned external, high-frequency magnetic alternating field. The basic principle of this new approach is shown schematically in Figure 6.

Our developments to date have concentrated on the synthesis of various magnetic nanoparticles and their inductive heating behaviour [52,53]. Methods for coupling the CD4 receptor have also been elaborated with the aid of model proteins. Figure 7 documents some typical heating experiments with magnetic suspensions, which clearly prove that the required temperatures of $50^{\circ} \mathrm{C}$ and higher can basically be achieved. Starch stabilised magnetic nanoparticles to which CD4 is attached have now been able to be synthesised. In vitro investigations into their biochemical functionality are currently being performed.

\section{CONCLUSION}

By applying a water-in-oil suspension cross-linking technique, novel magnetic polymer particles on the basis of polyvinylalcohol have been prepared for bioseparation purposes. The outstanding physical and biochemical properties of the novel separation media have been 
exploited to separate and isolate blood group antibodies from human plasma, nucleic acids and human T-cells. Thus, it could be demonstrated that biomagnetic separation technique represents a powerful alternative to conventional separation methods, particularly with respect to practicability, speed and accuracy.

The overall versatility of the magnetic bead technology has been shown by using magnetic nanoparticles for a new AIDS therapy approach. The magnetic nanoparticles which are designed to specifically bind to the AIDS virus (HIV) can be heated up in an external high frequent magnetic field to temperatures $>50^{\circ} \mathrm{C}$ which are required to destroy the HI-virus.

\section{References}

[1] Guesdon, J. L. and Avrameas, S. (1977). Immunochemistry, 14, 443.

[2] Molday, R. S., Yen, S. P. S. and Rembaum, A. (1977). Nature, 268, 437.

[3] Margel, S. and Offarim, M. (1983). Analytical Biochemistry, 128, 342.

[4] Margel, S., Zisblatt, S. and Rembaum, A. (1979). J. Immunological Methods, 28, 341.

[5] Margel, S., Beitler, U. and Ofarim, M. (1982). J. Cell Science, 56, 157.

[6] Schröder, U. L. and Mosbach, K. (1983). Int. Patent Application W083 91738.

[7] Mosbach, K. and Schröder, U. (1979). FEBS Letters, 102, 112.

[8] Ugelstad, J., Mork, P. C., Mfutakamba, H. R., Soleimany, E., Norhuus, I., Schmid, R., Berge, A., Ellingsen, T. and Aune, A. (1983). In: Science and Technology of Polymer Colloids, Vol. I, Poehlein, G. W. et al. Eds., Martinus Nijhoff Publishers, Boston, p. 51.

[9] Ugelstad, J., Ellingsen, T., Berge, A. and Helgee, O. B. (1987). U.S. Patent $4,654,267$.

[10] Daniel, J. C., Schuppiser, J. L. and Tricot, M. (1982). US Patent 4,358,388.

[11] Yanase, N., Noguchi, H., Asakura, H. and Suzata, T. (1993). J. Appl. Polymer Science, 50, 765.

[12] Reimers, G. W. and Khalafalla, S. E. (1974). U.S. Patent 3,843,540.

[13] Rosensweig, R. E., U.S. Patent 3,917,538.

[14] Stierstadt, K. (1990). Physikalische Blätter, 46, 377.

[15] Chagnon, M. S., Groman, E. V., Josephson, L. and Whitehead, R. A., U.S. Patent 4,628,037.

[16] Gries, H., Mützel, W., Zurth, C. and Weinmann, H., Ger Offen. DE 3508000 A1.

[17] Lübbe, A. S., Bergemann, C., Huhnt, W., Fricke, T., Riess, H., Brock, J. and Huhn, D. (1996). Cancer Res., 56, 4694.

[18] Weissleder, R., Chambon, C., Clement, O., Le Blanche, A., Schouman-Claes, E. and Frija, G. (1993). Magn. Res. Imaging, 11, 509.

[19] Schmitz, B., Radbruch, A., Kümmel, T., Wickenhauser, C., Korb, H., Hansmann, M., Thiele, M. and Fischer, R. (1994). Eur. J. Haematol., 52, 267.

[20] Widder, K. J., Morris, R. M., Poore, G., Howard, D. P. and Senyei, A. E. (1981). Proc. Natl. Acad. Sci., 78, 579.

[21] Müller-Schulte, D., Füssl, F. and de Cuyper, M. (1997). In: Scientific and Clinical Applications of Magnetic Carriers, Häfeli, U. et al. Eds., Plenum Press, New YorkLondon, p. 93. 
[22] Ficek, B. J. and Peppas, N. A. (1993). J. Controlled Release, 27, 259.

[23] Fujisato, T., Okada, T., Tabata, Y. and Ikada, Y. (1973). Polymer Preprints, Japan (Engl. Ed.), 39, 1069.

[24] Kim, C.-J. and Lee, P. I. (1992). Pharm. Res., 9, 10.

[25] Hyon, S.-H., Cha, W. and Ikada, Y. (1994). J. Biomat. Sci., 5, 397.

[26] Burg, K., Mauz, O., Noetzel, S. and Sauber, K. (1988). Angew. Makromol. Chem., 157, 105.

[27] Dixon, D. R. (1980). Macromol. Sci.-Chem., A14, 153.

[28] Chang, H. N. (1982). Desalination, 42, 63-77.

[29] Chun, H.-J., Kim, J.-J. and Lee, S.-H. (1990). Polymer J., 22, 477.

[30] Huang, R. Y. and Rhim, J. W. (1993). Polymer Int., 30, 123.

[31] Giusti, P., Latteri, L. and Barbani, N. (1993). J. Mat. Sci. in Medicine, 4, 538.

[32] Zhujun, Z., Zhang, Y. and Wangbai, M. (1989). Anal. Chem., 61, 202.

[33] Müller-Schulte, D. (1996). PCT Application WO/EP96/02398.

[34] Müller-Schulte, D., Manjini, S. and Viayalakmi, M. A. (1991). J. Chromatogr., 539, 307.

[35] Müller-Schulte, D., Presented at the Xth Int. Symposium on Hemoperfusion, Adsorption and Immobilized Reactants, Rome, Sept., 1990.

[36] Ikada, Y., Iwata, H. and Horii, F. (1981). J. Biomed. Mat. Res., 15, 697.

[37] Freiburghaus, C., Ohlson, S. and Nilsson, I. M. (1988). In: Methods in Enzymology, Vol. 137, Mosbach, K. Ed., Academic Press, San Diego, p. 458.

[38] Parker, T. S. and Studebaker, J. F. (1988). In: Methods in Enzymology, Vol. 137, Mosbach, K. Ed., Academic Press, San Diego, p. 466.

[39] Müller-Schulte, D. (1993). Radiat. Phys. Chem., 42, 891.

[40] Chang, T. M. S. (1988). In: Methods in Enzymology, Vol. 137, Mosbach, K. Ed., Academic Press, San Diego, p. 444.

[41] Müller-Schulte, D. and Daschek, W. (1995). Radiat. Phys. Chem., 46, 1043.

[42] Dumitriu, S. and Dumitriu, M. (1994). In: Polymeric Materials, Dumitriu, S. (Ed.), Marcel Dekker, New York, p. 435.

[43] Finch, C. A. (1992). In: Polyvinyl Alcohol-Developments, Finch, C. A. Ed., Chichester, John Wiley \& Sons, p. 763.

[44] Osterwalder, B., Gratewohl, A., Nissen, C. and Speck, B. (1986). Blut, 53, 379.

[45] Meza, M. (1997). In: Scientific and Clinical Applications of Magnetic Carriers, Häfeli, U. et al. Eds., Plenum Press, New York and London, p. 303.

[46] Sharma, P., Lönneborg, A. and Stougaard, P. (1993). Bio/Techniques, 15, 610.

[47] Lee, Y.-H. and Vacquie, V. D. (1992). Anal. Biochem., 206, 206.

[48] Hawkins, T. L. and O'Connor-Morin, T. (1994). Nucleic Acids Res., 22, 4543.

[49] Bergemann, C., Müller-Schulte, D., Oster, J., a Brassard, L. and Lübbe, A. S. (1999). J. Magnet. Magn. Mat., 194, 45.

[50] Haukanes, B.-I. and Kvam, C. (1993). Bio/Technology, 11, 63.

[51] Advances in Biomagnetic Separation (1994). Uhlen, M. et al. Eds., Eaton Publishing Co., Natick, MA.

[52] Müller-Schulte, D., Füssl, F., Lueken, H. and de Cuyper, M. (1997). In: Scientific and Clinical Applications of Magnetic Carriers, Häfeli, U. et al. Eds., Plenum Press, New York and London, p. 517.

[53] Müller-Schulte, D. and Lueken, H. (1998). BIOforum, 21, 504. 